\title{
A Systematic Literature Review of Multi-Criteria Analysis Model Methods on Sustainability Weighting for Ethanol Plant
}

\author{
Norfazilah Abdul Halim ${ }^{1}$, Nor Zalina Kasim ${ }^{1 *}$, Aliff Radzuan Mohamad Radzi ${ }^{1}$ and Faiz bin Mohd Turan ${ }^{2}$ \\ ${ }^{I}$ Faculty of Chemical Engineering, Universiti Kuala Lumpur-Malaysian Institute of Chemical and Bioengineering \\ Technology, Bandar Vendor, Lot 1988,19, 78000 Alor Gajah, Melaka, Malaysia \\ ${ }^{2}$ Faculty of Manufacturing, Universiti Malaysia Pahang, 26600 Pekan, Pahang, Malaysia
}

\begin{abstract}
The sustainability weighting is crucial as it is practically implemented into sustainability evaluation, especially in industrial development. Sustainability is about the interconnection between three aspects of sustainability impact such as economic impact, environmental impact, and social impact. Multi-Criteria Analysis (MCA) model play important roles to measure the weighting for each impact according to the scenario and criteria selected based on scientific rules and robust statistical methods. However, there were insufficient studies on the existing literature sustainability weighting model from MCA method for the ethanol plant. Hence, the present paper demonstrates a systematic literature review of MCA model methods on sustainability weighting for the ethanol plant. There are two steps involved in systematic literature reviews: formulation of the research question and systematic searching strategies consisting of identification, screening, eligibility, quality appraisal, data abstraction and analysis. The review is based on leading databases; Scopus - ScienceDirect, Springer, Taylor and Francis, and one supporting database - Google Scholar. From the review, the preferable MCA weighting model for sustainability evaluation of ethanol plants is integrated Analytical Hierarchy Process (AHP)' rather than 'standalone AHP'. The paper offered a significant contribution to the body of knowledge and sustainability evaluation purposes.
\end{abstract}

Keywords: systematic literature review; ethanol plant; multi-criteria analysis; Analytical Hierarchy Process (AHP); weighting

\section{INTRODUCTION}

Sustainability has become a trending topic that has attracted many researchers, stakeholders and policy makers as the world needs to be preserved for our future. According to the 2030 agenda for sustainability development, there are 17 sustainability development goals (SDG's) agreed by 193 member states of the United Nations. The SDG represents a leading tool of action for the planet, people and prosperity. It is also integrated and balances the three dimensions of sustainable development, which are economic, environmental and social. SDG is executing globally, and the impacts of industrial process plants are subjected to 9 goals such as, the social impacts produced by industrial plants will affect human health and safety, therefore Goal 3 (good health and well-being) and Goal 11 (sustainable cities and communities) support in reducing impacts to ensure healthy lives at all ages and making their surrounding area safe, resilient and sustainable. Next, are present again for environmental impact, in Goal 6 (clean water and sanitation), Goal 7 (affordable and clean energy), Goal 9 (industry, innovation and infrastructure), Goal 12 (responsible consumption and production), Goal 13 (climate action), Goal 14 (life below water), Goal 15 (life and land) promoted to build inclusive, resilient and sustainable pollution management (United Nations, 2020). Moreover, the goals also protect the ecosystem as well as urge everyone to take action to combat climate change and its impacts. The stricter

*Corresponding author: zalina.kasim@unikl.edu.my 
policy will increase the concern to industry in making this world less polluted, social friendliness, but at the same time reduce the cost for economic benefit.

The objective of this study is to determine the MCA models for sustainability assessment purposes. The selected industrial plant for this study is the ethanol plant. There are two methods to produce ethanol, by petrochemical process or by fermentation. Roozbehani et al. (2012) stated that the ethanol plant is one of the important contributors to country economies as their energy security strategies enable to accomplish the demand for medical purposes such as antibacterial hand sanitiser gels and medicinal solvents due to ethanol's ability to kill organisms by denaturing proteins and dissolving their lipids. The effectiveness against most bacteria, fungi and viruses is also supported by Golin et al. (2020). Other than that, synthetic ethanol is commonly used as a clean-burning fuel source, chemical/industrial solvent and vital substance in manufacturing industries. The fuel additive from ethanol production successfully received interest from academics, researchers, and industrial experts (Abedin et al., 2016). Some of the past researchers concluded that the usage of less than $40 \%$ of ethanol together with emulsifier or co-solvent should work together in blended fuel to maintain the stability of diesel (Pidol et al., 2012) hence, reducing harmful emission of $\mathrm{CO}, \mathrm{CO} 2, \mathrm{SOx}$, smoke opacity and particulate matter.

The sustainability of the petrochemical process plant is another significant issue due to its sustainability is varied from biorefinery plants in terms of raw material used, which are from petrochemical sources. Some of the ways to minimise the sustainability impacts of the petrochemical plant are by tracking the wastes that come from the operation, incorporate some recycling routes and introducing MCA at the early stage of plant design (Serna et al., 2016). The framework for sustainability assessment is important as to ensure decision-makers can justify their task by providing qualitative and quantitative analysis; hence, the best solution will be chosen systematically. According to Behzad et al. (2019) and Singh et al. (2012), sustainability is evaluated from indices and rating systems such as the selection of appropriate indicators (environmental, economic, social and technical criteria), normalisation, criteria weighting, aggregation and sensitivity analysis. The consequences of poorly conducted indices and weighting is it will lead to misinterpreted and misleading results.

MCA has attracted researchers to its potential usefulness for sustainability weighting evaluation. In the recent study by Martinkus et al. (2019), MCA methods have been used for decision-making due to their ability to analyse qualitative and quantitative data simultaneously. Some of the purposes of MCA methods are to use criteria value for further assessment, to determine a problem, to define the significance of each criterion, and to evaluate alternatives in scale values. MCA has the characteristics of simplicity and clear judgment of the correlation between criteria and a powerful tool for balancing stakeholder principles and priorities with respect to multiple criteria and provides useful guidance to help the dynamic decision-making process. Over the past 20 years, MCA methods have become a reliable solution for decision analysis, especially in engineering, management, and other fields. H. Wang et al. (2017) stated that MCA had been used in many fields of science, such as environmental resource management. However, the most important before evaluation are selection of the model, type of weighting mechanism and treatment/solution of missing value as they can be varied based on appropriate communities of interest.

\section{MATERIALS AND METHOD}

\section{A. Formulation of Research Question}

PICo has been used as a tool to guide authors in formulating research questions for the review study. There are three main concepts of PICo for social science purpose, which are Population, Interest, and Context based on Samsuddin et al. (2020) study. Meanwhile, for clinical purpose, different PICo which involved Population, Intervention, Context and Outcome, have commonly been used to aid researchers and healthcare practitioners to determine potential risks of bias and evidence related to diseases in the literature (Davies, 2011). For this study, the research question was determined by following social science's PICo concepts, namely researcher and industrial (Population), MCA models for sustainability weighting (Interest) and ethanol plant (Context). It will then be formulated to - What are the MCA models for sustainability weighting practiced by researchers and industrial in ethanol plants? 


\section{B. Systematic Searching Strategies}

The systematic searching strategies have five main processes, which are identification, screening, eligibility, quality appraisal, and data abstraction and analysis.

\section{Identification}

The identification process involved searching synonym keywords for related terms of the main keywords. For this study, the synonym of main keywords, namely Multi-Criteria Analysis or MCA, ethanol plant, chemical plant, weighting and sustainability, will be searching for more findings on related articles. The identification process was based on Research Question. The process also used some keywords by past researchers or suggested by the main database and online thesaurus.

The full search string can be developed by authors by expanding the existing keywords using Boolean operator, phrase searching and a wild card on the main databases, namely Scopus - Science Direct, Springer and Taylor and Francis. The advantage in using three databases is due to their high number of articles published yet acknowledged for their article's quality, advanced searching functions offered, and multidisciplinary focus, including studies related to sustainability. Google Scholar is chosen as an additional database because, according to Gusenbauer, (2019) about 389 million documents are available in that database and hence, give an advantage for researchers to search the related articles.

Based on this searching process, 2595 articles were found related to the research question. Combination of keywords searching were aid by Boolean operator (AND,OR) and some truncation character ( \{\}$\left.,(), “,{ }^{*}\right)$. However, truncation or wild card such as asterisk $\left(^{*}\right)$ code is not supported for Elsevier searching database during this study. Even though the "*' code play an important role in widen the words searching, for example, "sustainabl*" for sustainable, but it can be resolved by adding the word sustainable or other synonymous words, next, system will give you the same outcome as desired. The other factor that led to three search strings for article searching was the Boolean operator's restriction to eight uses only. The three relationships were:

\footnotetext{
i. $\quad$ MCA - weighting -plant

ii. Sustainability - weighting - plant

iii. Sustainability - MCA - plant
}

The other limitation arose in Springer and Taylor \& Francis quest process; there were insufficient articles and book chapters if they were narrowed down using the TITLE-ABSKEY formula. If one of the formulas does not exist in the search strings, manual selection is required based on the title, abstract and keyword. Some of the search strings used for this study:

Table 1 . Search strings according to database

\begin{tabular}{ll}
\hline Database & Search String \\
\hline ScienceDirect & (("multi criteria analysis" OR "MCA" OR \\
& "multi criteria decision" OR "multi \\
& objective") AND ("weighting" OR \\
& "sustainable weight" OR "weighting \\
& score") AND ("chemical plant" OR \\
& "ethanol plant")) \\
& TITLE (("environment" OR "economic" \\
& OR "social" OR "sustainability") AND \\
& ("weight" OR "weighting" OR \\
& ("cheminable weight or score") AND
\end{tabular}

(("environment" OR "economic" OR "social" OR "sustainability") AND ("multi criteria analysis" OR "MCA" 'OR "multi criteria decision") AND ("chemical plant" OR "ethanol plant"))

\begin{tabular}{ll}
\hline Springer & TITLE (("multi criteri* analysis" OR \\
& "MCA" OR "MCDA" OR "multi criteri* \\
& decision*" OR "multi objectiv*") AND \\
& ("weighting*" OR "sustainabl* weight*" \\
& OR "weighting scor*") OR \\
& ("environment*" OR "economic*" OR \\
& "social*" OR "sustain*") AND ("chemical \\
& plant" OR "ethanol plant")) \\
\hline Taylor \& & TITLE-KEY(("multi criteri* analysis" OR \\
Francis & "MCA" OR "MCDA" OR "multi criteri* \\
& decision*" OR "multi objectiv*") AND \\
& ("weighting*" OR "sustainabl* weight*" \\
& OR "weighting scor*") OR \\
& ("environment*" OR "economic*" OR \\
& "social*" OR "sustain*") AND ("chemical \\
& plant" OR "ethanol plant")) \\
\hline Google & (("multi criteria* analysis" OR "MCA" OR \\
Scholar & "MCDA" OR "multi criteria* decision*" \\
& OR "multi objective*") AND \\
& ("weighting*" OR "sustainable* weight*" \\
& OR "weighting scor*") AND ("chemical \\
plant" OR "ethanol plant" OR & OR \\
& "oleochemical plant")
\end{tabular}

\section{Screening}

A screening process is a process in which requirements for inclusion and exclusion have been distinguished based on the time range (year), language, type of document and 
application area. Table 2 shows the details of the screening In this phase, only 61 articles were selected.

sorting process for this study.

\section{Quality appraisal}

Table 2. List of inclusion and exclusion in screening process

\begin{tabular}{lll}
\hline Criteria & Inclusion & Exclusion \\
\hline $\begin{array}{l}\text { Period } \\
\text { range }\end{array}$ & 2012-2019 & $<2012$ \\
$\begin{array}{l}\text { Document } \\
\text { Type }\end{array}$ & $\begin{array}{l}\text { Article journal } \\
\text { (empirical } \\
\text { data) }\end{array}$ & $\begin{array}{l}\text { Article } \\
\text { chapters in bongliew, } \\
\text { conference } \\
\text { proceeding } \\
\text { Non-industrial }\end{array}$ \\
$\begin{array}{l}\text { Application } \\
\text { area }\end{array}$ & $\begin{array}{l}\text { Chemical plant } \\
\text { or industrial }\end{array}$ & \begin{tabular}{l} 
\\
\hline
\end{tabular}
\end{tabular}

The quality of articles will be presented by quality assessment. The remaining articles were ranked according to the ability to answer all the questions below:

1. Has the multi-criteria methods been discussed in detail?

2. How the method measures for weighting proposes?

3. Has the study related to sustainability?

4. If the study was related to sustainability evaluation of chemical plant, what was the common mca method?

The proposed research-based screening method is important since impossible for researchers to review large numbers of articles (Kitchenham \& Charters, 2007). The timeline restriction was from 2012 until 2019 due to the study had been done during the year 2020 and the year still not ended yet this study according to Samsuddin et al. (2020). Other than that, a lot of research regarding weighting for sustainability evaluation bloom in 2012 onwards.

In addition, conference proceedings, paper analysis and book chapters were excluded through screening process, and only article journals that have analytical evidence and are related to the chemical industry are selected in this research. To prevent confusion during data analysis, English publication is also one of the inclusive requirements rather than other languages.

Through this process, 2242 articles were omitted as they did not meet the inclusion requirements, and due to overlap, 4 articles were deleted by using Systematic Review Accelerator - Deduplicate Module Software. The remaining 349 articles were used for further process, which is eligibility.

\section{Eligibility}

Eligibility is the process where the authors deduce the number of articles manually as exclusion criteria and at the same time, ensure the remaining articles fulfil all criteria. The abstract and title of the articles were monitored, and 286 articles were excluded due to:

i. Emphasis on the non-chemical industry

ii. Focus on either one impact rather than three sustainability impacts

iii. Focus on non-engineering rather than chemical plant areas

iv. Type of papers- book chapters or review paper

There are three articles' levels based on Samsuddin et al. (2020) namely high, moderate, and low. The remaining articles will be categorised, and only articles in two classifications, such as high and low, will be reviewed. The quality rank should be focused on MCA methods for sustainability assessment in chemical plants. This process had ranked 29 articles as high, 16 articles as moderate and 16 articles as low. The remaining 45 articles were eligible for review at both high and moderate levels.

\section{Data abstraction and analysis}

Twenty-two articles including diverse research designs such as qualitative, quantitative and mixed-method approaches were chosen after the inclusion and exclusion procedure. The researcher will read particularly on abstract, results and discussions to ensure any information and data found should be reflected and answer the research question. Next, iterative comparison can be computed and tabulated between abstracted data as per below relationship:

i. What is the type of MCA method used for study?

ii. Is there a weighting score of sustainability stated?

iii. How are the papers are related to chemical plants?

iv. Do papers discuss MCA together with its implementation?

v. Why usage of MCA is related to sustainability?

The descriptive method in the thematic form will reduce the finding and help the researcher to merge with other data analysis techniques (Samsuddin et al., 2020). The flow diagram (Figure 1) demonstrates systematic review as per shown below: 


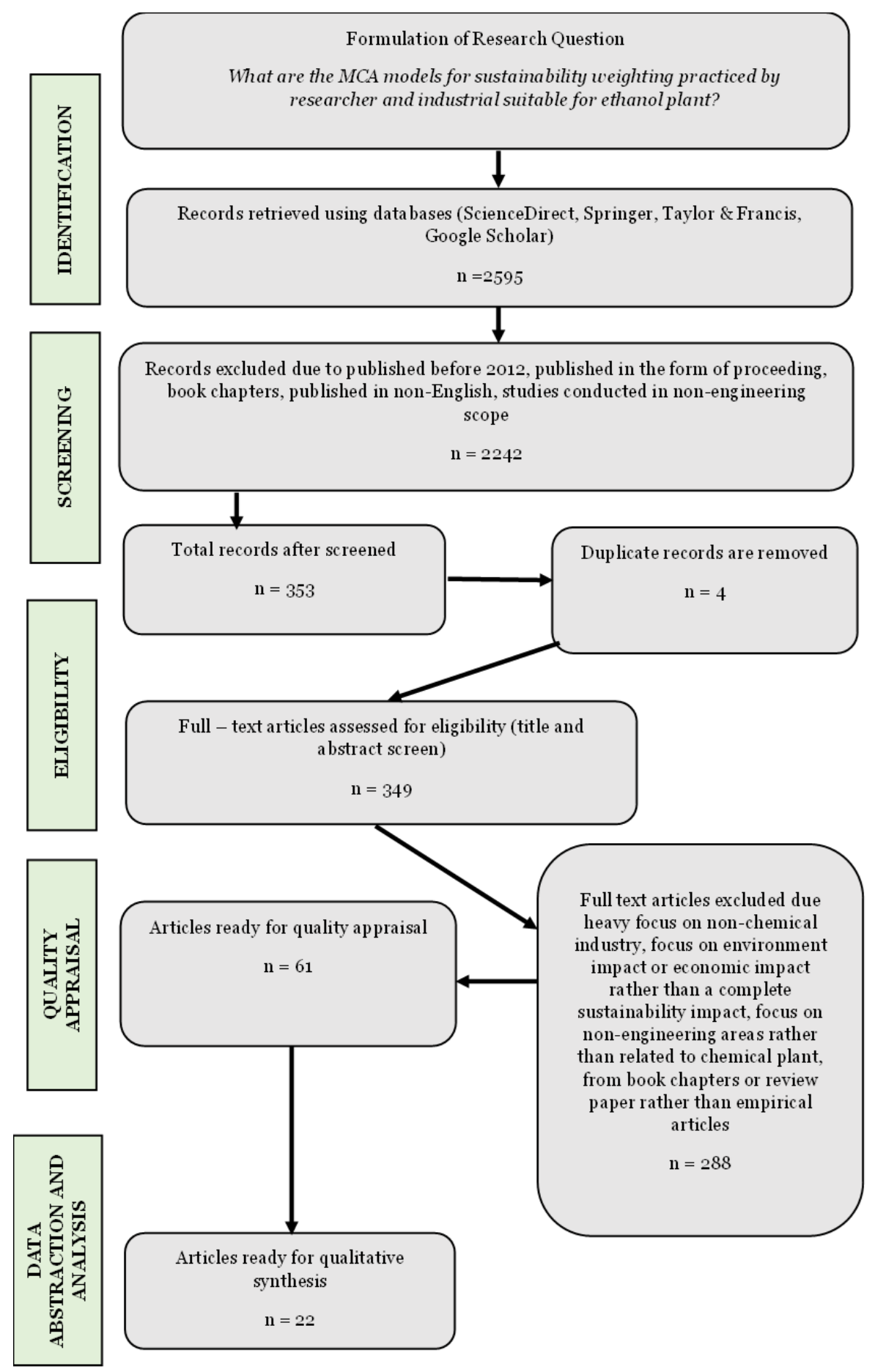

Figure 1. Systematic Literature Review (SLR) flow diagram (adapted from Samsuddin et al. (2020))

\section{RESULT AND DISCUSSION}

\section{A. Review Findings}

Based on Table 3 shown below, 22 final articles were abstracted and analysed to fulfil the objective as to determine the suitable MCA models for sustainability weighting of ethanol plant. The number of articles for process plants, including chemical plants, industrial plants and other plants are 11, 7 and 4 articles. All relationships based on research questions were addressed in about 12 papers meanwhile, others only listed two of the relationship. 
Table 3. Tabulated data findings referring to research questions

\begin{tabular}{|c|c|c|c|c|c|c|c|}
\hline \multirow[t]{2}{*}{ STUDIES (REF.) } & YEARS & $\begin{array}{l}\text { APPLICATION } \\
\text { AREA/SCOPE }\end{array}$ & RELATIOI & SHIP WI & LOW: & $\begin{array}{l}\text { METHODS } \\
\text { IMPLEMENTATION }\end{array}$ & $\begin{array}{l}\text { WEIGHTING } \\
\text { SCORE }\end{array}$ \\
\hline & & & WG & SUST & PL & & SUST (all) \\
\hline IKE C et al. & 2016 & $\mathrm{CP}$ & $x$ & $\mathrm{x}$ & & AHP & \\
\hline BEHZAD et al. & 2018 & $\mathrm{CP}$ & $x$ & $x$ & $x$ & AHP, LIKERT & $x$ \\
\hline RANJAN et al. & 2014 & $\mathrm{CP}$ & & $x$ & $x$ & DELPHI & \\
\hline NATALIE et al. & 2019 & $\mathrm{CP}$ & $x$ & $x$ & $x$ & AHP & $x$ \\
\hline HOW BIN SHENG et al. & 2018 & $\mathrm{CP}$ & $x$ & $x$ & $x$ & AHP & $x$ \\
\hline FELICE et al. & 2013 & IP & $x$ & $x$ & & AHP & \\
\hline ANTONIO et al. & 2012 & $\mathrm{OP}$ & $x$ & $x$ & & AHP & $\mathrm{x}$ \\
\hline FAISAL et al. & 2014 & IP & $x$ & $x$ & $x$ & FUZZY & \\
\hline JEONG et al. & 2017 & $\mathrm{CP}$ & $x$ & $x$ & & AHP, FUZZY, DEMATEL & $x$ \\
\hline KATIA et al. & 2019 & $\mathrm{CP}$ & $x$ & $x$ & $x$ & DELPHI & \\
\hline RUOJUE et al. & 2019 & OP & $x$ & $x$ & $x$ & BWM, AHP & \\
\hline MATHIYAZHAGAN et al. & 2017 & IP & $x$ & $x$ & & AHP, FUZZY, DEMATEL & \\
\hline MATZEN et al. & 2015 & $\mathrm{CP}$ & $x$ & $x$ & $x$ & PUGH & \\
\hline HS QI et al. & 2013 & $\mathrm{CP}$ & $x$ & $x$ & $x$ & FUZZY & \\
\hline JINGZHENG et al. & 2014 & $\mathrm{CP}$ & $x$ & $x$ & $x$ & FUZZY & \\
\hline YAZDI et al. & 2018 & IP & $x$ & $x$ & $x$ & FUZZY, AHP & $x$ \\
\hline YAZDI et al. & 2017 & $\mathrm{CP}$ & $x$ & $x$ & $x$ & FUZZY, AHP & \\
\hline ROBERT et al. & 2018 & IP & $x$ & $x$ & & SCORE & $x$ \\
\hline HAO WANG et al. & 2017 & OP & $x$ & $x$ & $x$ & FUZZY, AHP & \\
\hline $\begin{array}{l}\text { HAO WANG et al. } \\
\text { LEI WANG et al. }\end{array}$ & 2018 & IP & $x$ & $x$ & & FUZZY, AHP & \\
\hline \multirow{2}{*}{$\begin{array}{l}\text { ZHAOYANG et al. } \\
\text { FU ZHAO } \text { et al. }\end{array}$} & 2019 & OP & $x$ & $x$ & & AHP & $x$ \\
\hline & 2012 & IP & $x$ & $x$ & & AHP & \\
\hline & $\begin{array}{l}\mathrm{CP}=\text { Chemical Plant } \\
\mathrm{EP}=\text { Ethanol Plant } \\
\mathrm{OP}=\text { Other Plant } \\
\text { IP = Industrial Plant }\end{array}$ & $\begin{array}{l}\text { SUST }=\text { sus } \\
\text { WG = weig } \\
\text { PL = plant }\end{array}$ & $\begin{array}{l}\text { ainability } \\
\text { ting }\end{array}$ & $\begin{array}{l}\text { AHP = } \\
\text { DEMA } \\
\text { and Ev } \\
\text { TOPSI } \\
\text { Prefere } \\
\text { Solutio }\end{array}$ & $\begin{array}{l}\text { ytical } \\
=\text { Deci } \\
\text { ion La } \\
\text { echnic } \\
\text { by Sin }\end{array}$ & $\begin{array}{l}\text { erarchy Process } \\
\text { on Making Trial } \\
\text { ratory } \\
\text { e for Order } \\
\text { larity to Ideal }\end{array}$ & \\
\hline
\end{tabular}

\section{B. Relationship between MCA and Other Criteria}

\section{Relationship between MCA and process plant}

Out of 22 selected papers, there are three kinds of process plants such as chemical plants, industrial plants and other plants. Due to the lack of petrochemical ethanol plants in MCA study, several papers have been selected that may be relevant to the ethanol plant. In biorefinery plants, most past researchers discuss the system of sustainability with focus on biomass supply chains, site selection, biomass process in biorefinery site and sustainability assessment methodologies (How \& Lam, 2018; Jeong \& Ramírez-Gómez, 2018a; Jesus et. al., 2019a; Martinkus et. al., 2019a; Parajuli et al., 2015a). Analytical hierarchy process (AHP) has been used by How \& Lam (2018) as to determine the priority scale assigned to solve supply chain problem in transportation and technology selected for a case study in Johor, Malaysia. Jeong \& Ramírez-Gómez, (2018) and Martinkus et al. (2019) also implement AHP to determine the weighting factor and a pairwise comparison to measure the comparative significance of each sustainability parameters for developing final site selection for biomass process plant. Meanwhile, the DELPHI method presented in the form of web questionnaires has been used by Jesus et al. (2019) and Parajuli et al. (2015) to two groups: academic experts and industry experts for sustainability purposes in bioethanol plant. Some petrochemical plants use a combination of Fuzzy and AHP in their study to evaluate the risk process for an ethylene plant. It helps stakeholders/decision-makers accept initiatives by incorporating goal programming, AHP and Fuzzy theory. The hybrid approaches were also used to illustrate the prioritisation of hydrogen economy roadmap design plans, adequate budget preparation, and resources allocation to support China's hydrogen economy (Ren et. al., 2015; Yazdi \& Kabir, 2017a). 
For this review, industrial plants reflect the civil and manufacturing sectors, such as automotive, electronic factories and marine sectors. The purpose of AHP as one of the MCA models is to define the critical factors required to assess the "degree" of environmental sustainability, such as energy-saving, environmental impacts and percent recyclable content (De Felice et. al., 2013a; Zhao et al., 2012). Meanwhile, the combination of AHP-Fuzzy and DEMATEL has been used for risk analysis in offshore process industries to resolve ambiguity in failure data as well as to assess the dependency between incidents. Other than that, it was also used in shipping safety investment decision-making for marine facilities (Mathiyazhagan et. al., 2018; L. Wang et. al., 2018; Yazdi \& Kabir, 2017). For other plants category, it represents plants that provide energy supply and source management. In choosing the best approach for energy sustainability evaluation and water management, the studies used the same method - AHP for MCA. However, for energy sustainability, the past researcher added one more method which is Best-Worst-Method (BWM) (Freitas \& Magrini, 2013; Lin et. al., 2019a; Yang et al., 2019). However, H. Wang et al. (2017) use an integrated approach for groundwater management decision-making, which was a hybrid of AHPFuzzy, to reflect the uncertainties that occurred with weights of criteria.

\section{Relationship between MCA and sustainability purpose}

Decision-making for sustainability requires assessing different criteria considering three common sustainability dimensions, such as economic, environmental and social dimensions. All selected articles address sustainability together with MCA and from the analysis, less than fifty percent of articles include all three elements of sustainability. There are three categories that are discussed under this relationship. First is economic as for example, at the early stage of design, capital budgeting or budgetary control is used to assess the best long-term project strategies for an organisation. It is the mechanism by which an organisation decides whether it is worth undertaking projects such as constructing a new plant or investing in new product development. Meanwhile, in China, some feasibility studies regarding the transition to the hydrogen economy for a more sustainable future grab attention from researchers and stakeholders (Matzen et. al., 2015a; Ren et al., 2015). Other than that, economic evaluation dealing with various measures in the decision-making process for selection methanol production from renewable or non-renewable resource have also been studied under this category. From all stated studies, 'integrated AHP' has been used rather than 'standalone AHP' for sustainability evaluation, especially in economic impact. In addition, some of the economic tools that used for economic assessment were Cost Benefit Analysis (CBA), Aspen Cost Simulator and LCA (Ehie et. al., 2016a; Matzen et. al., 2015a; Ren et al., 2015).

The second category that gains great concern globally is the environmental impact. To satisfy customers and environmental regulation policies along with improvement of environmental efficiency, the adoption of environmental management practices is necessary in any industry (Matzen et al., 2015a). Environmental impact in chemical industries may potentially expose to the various threat to nature and community. Therefore the factor of impacts should be clearly defined and reduced from getting worst (Parajuli et al., 2015). More recently, instruments such as Environmental Impact Analysis (EIA), Life Cycle Analysis and Excel-based sustainability evaluator have been used along with MCA for environmental impact assessment (Parajuli et. al., 2015; Zhao et al., 2012). Next, MCA enables stakeholders to refine some alternatives under environmental aspects, such as the list of biorefinery locations, list of supplier or supply chain selection, the routes of chemical plants, and restructure of management priority. For example, De Felice et al. (2013) implement AHP to describe a relevant classification of electric waste management in terms of performance tracking and to determine the priority or ranking of potential measures to be taken to enhance the sustainability of the integrated system based on their preferences using overall metric weights. To deal with various metrics in the decisionmaking method for comparisons of alternatives for different purposes in chemical plants, Król et al. (2019), Matzen et al. (2015) and Parajuli et al. (2015) used integrated AHP together with other techniques such as Pugh, Fuzzy and DELPHI method. All types of industries must comply sustainability policy, especially related to environmental risks due to the restrictions for licensing new operations and for public acceptance. Based on studies, environmental risks will 
affect the business and the main purpose of profit businesses is to provide a sustainable economic return to its shareholders for the long term even when incorporated to economic, environmental and social demand (Ehie et. al., 2016a; Freitas \& Magrini, 2013). The plant's sustainability can be accomplished by reducing environmental pollution at the same time enhancing the viability and social benefits.

The last category is social impact and about ten studies from selected articles classified it into two groups: safety impact and health impact. Nowadays, chemical industries are processing more dangerous substances within densely populated areas and there are increasingly complex risks resulting from the handling, manufacturing and distribution of these hazardous materials (Aqlan \& Mustafa Ali, 2014). Safety in process plant should be implemented at early stage of design to prevent misleading of risk assessment. Examples of failure in safety management such as in Iran, fire and explosion disaster accidents occurred at Rage Sefid well in 2017, Bouali Sina petrochemical company in 2016, and Naftshar well in 2010. The accidents attracted government, public, and all industrial sectors' inevitable attention and concern. The investigative reports showed that one of the major problems associated with these incidents is the lack of adequate protection investment plans (Yazdi et al., 2019). Companies must be able to adapt quickly to external and internal risk events and keep their company effective and dynamic to retain their profitability and prevent loss by implementing risk assessment in sustainability management (Aqlan \& Mustafa Ali, 2014; L. Wang et. al., 2018; Yazdi et. al., 2019; Yazdi \& Kabir, 2017). Aqlan et al. (2014) and Qi et al. (2015) use Fuzzy logic rules to treat the ambiguity inherent in the safety risks. Conversely, less attention has been given to health impacts based on the selected studies, as safety and risk assessment is the most discussed topic on social impact under sustainability (Jesus et al., 2019).

\section{Relationship between MCA and weighting purpose}

Sustainability weighting criteria can be divided into three categories, which are subjective weighting, objective weighting and combination weighting (Jeon et. al., 2014; Król et. al., 2019; Mathiyazhagan et. al., 2018; H Wang et al., 2017). Common tools for subjective weighing include consistent matrix analysis, pair-wise comparison, AHP, least- square method, and the Delphi method. The rating/ranking and prioritising of one metric/criteria against another will be obtained through this method. As defined in Król et al. (2019), the examples of objective weighting methods are the method for the order of choice by similarity to ideal solution (TOPSIS), methods for entropy evaluation, and the horizontal and vertical method. The entropy method primarily demonstrates to what degree the criterion represents the system's knowledge and the criteria-related uncertainties. For optimisation purposes, the weighting of horizontal and vertical methods will be produced by answering mathematical models. Based on Ehie et al. (2016), Jeong \& Ramírez-Gómez (2018) and Martinkus et al. (2019) studies, comparison among biobased products, fossil-fuel-based products and process routes are necessary for selection and sustainability assessment in a chemical process. Therefore, the pair-wise comparison tends to be useful for stakeholders to entertain preferences on the qualified sustainability indicators.

An integrated approach is proposed based on the combination of two types of weighting as per stated above. AHP and other MCA techniques will be linked together in one research study to represent the uncertainties associated with weights for the assessment and provide more precise measurements of the weights required in the mathematical programming models (Ehie et. al., 2016; Król et al., 2019). In the context of selecting the best distribution network, several researchers also used MCA and theory of multi-attribute value to determine alternatives for choosing a supply chain design and supplier selection based on their expertise (How \& Lam, 2018; Król et. al., 2019; Mathiyazhagan et al., 2018). Presently, MCA approaches have been commonly used in both the public and private sectors, such as transport, immigration, education, investment, governance, environment and energy (Lin et al., 2019).

Weights offer a way of assigning relative significance value when knowledge from literature and experts is required to assess their values quantitatively (Król et. al., 2019; Martinkus et. al., 2019; Yazdi \& Kabir, 2017). Several articles have included the weighting values associated with sustainability in their research. There are three groups of weighting values that will be discussed under sustainability: economic, environmental, and social. Basically, the 
weightage is aggregated from overall ranking (collected from individual criteria) using MCA models and then form into one unitless value for further assessment. Some of the assigned weighting for economic, environmental and social from selected articles are 0.25, 0.5, 0.25 (How \& Lam, 2018), 0.3, 0.3, 0.4 (Behzad et al., 2019), 0.33, 0.33, 0.33 (Brunet et al., 2012), 0.3, 0.2, 0.5 (Yazdi \& Kabir, 2017) and 0.15, 0.15, 0.6 (Jeong \& Ramírez-Gómez, 2018). However, Yang et al. (2019) assigned four weighting scores, which are 0.38, 0.11, 0.35, and 0.16 for economic, environmental, social and water resources. The weighting are mostly based on petrochemical and chemical process industry.

\section{Discussion}

The relationship between MCA and three other topics such as process plant, sustainability and weighting purpose has been reviewed for further discussion. AHP is one of the common techniques that attract researchers, academicians and industrial for the selection of alternatives based on qualitative and quantitative analysis. AHP aims to eradicate bias and reduce the inconsistency of professional decisions in the decision-making process by making pairwise comparisons between the criteria with respect to their impact on the plant and population. However, as the decisions depend on stakeholders' personal decisions, a different set of groups can produce a distinct set of weights for the same sample. This can inevitably lead to the inconsistency of the solutions generated (Król et. al., 2019; H. Wang et al., 2017). Therefore, to curb this issue, an integrated approach is required in selecting an appropriate weight for each sub-index analysis and provide more reliable predictions of the weights required in the mathematical programming models. Fuzzy, DELPHI, TOPSIS, DEMATEL and LIKERT are some of the established techniques that can be combined with current AHP. At the early stage of the ethanol plant design, the weighting by MCA models is used later in sustainability assessment. Therefore, from selected articles, AHP is adopted by most chemical process plants as the core method for weighting purposes and to resolve the inconsistency of ratings, hybrid of FuzzyAHP(FAHP), F-AHP DEMATEL and AHP-LIKERT are developed (Behzad et. al., 2019; Jeong \& Ramírez-Gómez, 2018b; Król et. al., 2019; Mathiyazhagan et. al., 2018; H Wang et al., 2017). Moreover, LIKERT and DELPHI technique is getting attention from researchers. These methods require questionnaires that will distribute to two groups' participants such as experts from the chemical industry and academic specialists for realistic estimation. Meanwhile, in Fuzzy, experts' requirement in taking part is equal or less than seven should be enough in answering all research questions for the study. For this study, the goal is to choose the weighting model for ethanol plant sustainability assessment at the early design stage. So, subjective weighting will be chosen rather than objective weighting (TOPSIS) as the optimisation phase has not yet been involved under this development study. By using integrated AHP, it can convert linguistic form to the quantitative index that gathered from expert's opinion and literature into mathematical modelling calculation.

Nowadays, industrial revolution is evolving rapidly in industry. The technologies such as Internet-of-Things (IoT), artificial intelligence (AI) and cloud computing have been introduced to replace many conservative ways, such as the trial-and-error bottom-up approach. High demand from global environment business causes the elimination of traditional approach as it is not effective and efficient in terms of time-consumed and cost (CIJ, 2017). For chemical plant, since the chemical properties of the product are still uncertain, it is possible to look for compliant molecular candidates by exploring them from existing databases or constructing them from a pool of molecular building blocks such as Aspen PLUS or HYSYS (Matzen et. al., 2015b; Yazdi \& Kabir, 2017). Moreover, CAMD will assist designers or engineers in designing large quantities of molecules with desired properties, developing plant flowsheets, determine appropriate operating conditions and mimic the actual process plant. From this reverse engineering approach, the reliable sustainability value can be obtained by affiliating it with MCA models. MCA's integrated technique and together with CAMD produce a systematic analysis for sustainability assessment of ethanol plant. Sustainability XML Evaluator in the form of excel format and life cycle analysis (LCA) are tools that are commonly used in sustainability assessment. LCA's advantage is that it provides details on environmental aspects from the cradle to the grave, thus attracting researchers to implement this tool for environmental study (Behzad et. al., 2019; Król et. al., 2019; Martinkus et al., 2019). On the other 
hand, Irfan et al. (2017). On the other hand, Irfan et al. (2017) stated that by using non-LCA tools such as Excel-based sustainability evaluators, measurement of GHG emission from process plant can be solved by using mathematical modelling, which are typically simpler and straightforward. Indeed, it is understandable that LCA application is widely used in biorefinery plants since the flow of concern is very specific, however difficult for a generic approach.

Sustainability consists of three dimensions of economic, environmental, and social. However, from the review, the health aspect is almost overlooked due to a lack of systematic evaluation methodology for social impact at the development phase. For example, workers are exposed to different risks in their working environment. However, it is difficult to define, prioritise risks and establish effective mitigation strategies due to the lack of quantitative mechanisms that take risk ambiguity and mitigation into account (Król et al., 2019). Therefore, to overcome the issue of health index and existing inherent safety system, integrated AHP models together with CAMD and sustainability tools are developed to ensure there is no sign of serious adverse effects on humans that caused by the industrial process. The common steps of MCA consist of indicators selection, weighting, normalisation, and sensitivity analysis. However, the outcome weighting scores among methods are different. For example, AHP and Fuzzy will be assigned a range from o to 1 . On the contrary, DELPHI, Pugh method and SCORE method indicates integer values that consist negative and positive number. These methods are mostly giving decision-makers a priority ranking by neglecting a group of criteria. Even so, to be used in the sustainability assessment of ethanol plant, the whole number, which is a positive number, is required, therefore AHP and Fuzzy and DEMATEL are preferable compared to other models. The integrated AHP involved interpreted expert opinions and literature finding in the form of value using MATLAB software.

Due to the inability to cope with hundreds of inherent ambiguity and vagueness during the decision-making process, standalone or traditional AHP is less recommended as it does not represent the human language in quantitative value. Therefore, to solve this gap, a reliable way to measure each expert's weight is required. One of the approaches to address the drawback of standalone AHP as discussed in the previous paragraph, is Integrated AHP. However, from the selected articles, if the emphasis is on biorefinery site selection, supplier selection and energy management, the only required MCA is standalone AHP for alternative ranking (How \& Lam, 2018; Martinkus et. al., 2019b; Yang et al., 2019). On the other hand, if the purpose of the analysis is to determine the process plant's sustainability, the weighting score from MCA, process simulation and sustainability tools should be involved in the study. These three proven tools are being applied in all selected articles to achieve their aim for sustainability purposes.

\section{CONCLUSION}

This study aims to define MCA models for sustainability weighting via systematic literature review to incorporate sustainability assessment of ethanol plant. This study offers significant contributions for knowledge purpose and industrial practice according to communities of interest. From the review, AHP technique results in the highest number of options for several purposes such as the selection of site, supply chain, management judgment, process routes and maintenance. Due to inconsistency of professional opinion in AHP, integrated AHP has been introduced to form quantify value from linguistic term and from this review, the most suitable model of MCA for ethanol sustainability assessment is FAHP.

\section{ACKNOWLEDGEMENT}

The authors from Universiti Kuala Lumpur would like to give special thanks to Assoc. Prof. Ir. Dr. Faiz bin Mohd Turan for his guidance through this review. No financial support received for the research. 


\section{REFERENCES}

Abedin, MJ, Kalam, MA, Masjuki, HH, Sabri, MFM, Rahman, SA, Sanjid, A \& Fattah, IR 2016, 'Production of biodiesel from a non-edible source and study of its combustion, and emission characteristics: a comparative study with B5', Renewable Energy, vol. 88, pp. 20-29.

Aqlan, Faisal \& Ebrahim Mustafa Ali 2014, 'Integrating lean principles and fuzzy bow-tie analysis for risk assessment in chemical industry', Journal of Loss Prevention in the Process Industries, vol. 29, no. 1, pp. 39-48.

Behzad, Masoud, Heetae Kim, Mehdi Behzad, \& Hadi Asghari Behambari 2019, 'Improving sustainability performance of heating facilities in a central boiler room by conditionbased maintenance', Journal of Cleaner Production, vol. 206, pp. 713-723.

Brunet, Robert, Reyes-Labarta, JA, Guillén-Gosálbez, G, Jiménez, L \& Boer, D 2012, 'Combined simulationoptimization methodology for the design of environmental conscious absorption systems', Computers and Chemical Engineering, vol. 46, pp. 205-216.

Davies, Karen Sue 2011, 'Formulating the evidence based practice question: a review of the frameworks', Evidence Based Library and Information Practice, vol. 6, no. 2.

Ehie, Ike C, Emmanuel O Oyatoye \& Innocent G Joseph 2016a, 'Capital project selection using an integrated AHPLP model: a case study in a developing economy', International Journal of Services and Operations Management.

Ehie, IC, Oyatoye, EO \& Joseph, IG 2016b, 'Capital project selection using an integrated AHP-LP model: a case study in a developing economy', International Journal of Services and Operations Management, vol. 24, no. 2, pp. 267-288.

De Felice, F, A Petrillo \& C Autorino 2013a, 'Proposal of a multi criteria approach for a sustainable management model of electrical and electronic equipment', in IFAC Proceedings Volumes (IFAC-PapersOnline).

De Felice, F, A Petrillo \& C Autorino 2013b, 'Proposal of a multi criteria approach for a sustainable management model of electrical and electronic equipment', IFAC Proceedings Volumes (IFAC-PapersOnline), vol. 46, no. 9, pp. 537-542.

Freitas, Antônio HA \& Alessandra Magrini 2013, 'Multicriteria decision-making to support sustainable water management in a mining complex in Brazil', Journal of Cleaner Production, vol. 47, pp. 118-128.
Golin, Andrew P, Dexter Choi \& Aziz Ghahary 2020, 'Hand sanitizers: a review of ingredients, mechanisms of action, modes of delivery, and efficacy against coronaviruses', American Journal of Infection Control.

Gusenbauer, Michael 2019, 'Google scholar to overshadow them all? comparing the sizes of 12 academic search engines and bibliographic databases', Scientometrics, Springer International Publishing, vol. 118, no. 1, pp. 177-214.

How, Bing Shen \& Hon Loong Lam 2018, 'Sustainability evaluation for biomass supply chain synthesis: novel Principal Component Analysis (PCA) aided optimisation approach', Journal of Cleaner Production, vol. 189, pp. 941961.

Irfan, Muhammad, Aleksandra Koj, Majid Sedighi \& Hywel Thomas 2017, 'Design and development of a generic spatial decision support system, based on artificial intelligence and multicriteria decision analysis', GeoResJ, vol. 14, pp. 4758.

Jeon, H, Kang, KE, Jeong, JS, Gong, G, Choi, JW, Abimanyu, H, Ahn, BS, Suh, DJ \& Choi, GW 2014, 'Production of anhydrous ethanol using oil palm empty fruit bunch in a pilot plant', Biomass and Bioenergy, vol. 67, pp. 99-107.

Jeong, Jin Su \& Álvaro Ramírez-Gómez 2018a, 'Optimizing the location of a biomass plant with a Fuzzy-DEcisionMAking Trial and Evaluation Laboratory (F-DEMATEL) and multi-criteria spatial decision assessment for renewable energy management and long-term sustainability', Journal of Cleaner Production, vol. 182, pp. 509-520.

Jeong, Jin Su \& Álvaro Ramírez-Gómez 2018b, 'Optimizing the location of a biomass plant with a Fuzzy-DEcisionMAking Trial and Evaluation Laboratory (F-DEMATEL) and multi-criteria spatial decision assessment for renewable energy management and long-term sustainability', Journal of Cleaner Production.

Jesus, Katia Regina Evaristo de, Torquato, SA, Machado, PG, Zorzo, CRB, Cardoso, BO, Leal, MRLV, Picoli, MCA, Ramos, RC, Dalmago, GA, Capitani, DHD \& Duft, DG 2019a, 'Sustainability assessment of sugarcane production systems: SustenAgro decision support system', Environmental Development, vol. 32, May, pp. 100444.

Jesus, Katia Regina Evaristo de, Torquato, SA, Machado, PG, Zorzo, CRB, Cardoso, BO, Leal, MRLV, Picoli, MCA, Ramos, RC, Dalmago, GA, Capitani, DHD \& Duft, DG 2019b, 
'Sustainability assessment of sugarcane production systems: SustenAgro decision support system', Environmental Development.

Kitchenham, Barbara \& Stuart Charters 2007, Guidelines for performing systematic literature reviews in software engineering, Technical Report, EBSE, UK, Durham.

Król, Aleksandra et al. 2019, 'Intuitionistic fuzzy TOPSIS method for green supplier selection problem', Journal of Cleaner Production, vol. 9, no. 1, pp. 11-22.

Lin, Ruojue, Yue Liu, Yi Man \& Jingzheng Ren 2019a, 'Towards a sustainable distributed energy system in China: Decision-making for strategies and policy implications', Energy, Sustainability and Society, vol. 9, no. 51.

Lin, Ruojue, Yue Liu, Yi Man \& Jingzheng Ren 2019b, 'Towards a sustainable distributed energy system in China: decision-making for strategies and policy implications', Energy, Sustainability and Society.

Martinkus, Natalie, Latta, G, Rijkhoff, SA, Mueller, D, Hoard, S, Sasatani, D, Pierobon, F \& Wolcott, M 2019a, 'A multicriteria decision support tool for biorefinery siting: using economic, environmental, and social metrics for a refined siting analysis', Biomass and Bioenergy, vol. 128, July, pp. 105330.

Martinkus, Natalie, Latta, G, Rijkhoff, SA, Mueller, D, Hoard, S, Sasatani, D, Pierobon, F \& Wolcott, M 2019b, 'A multicriteria decision support tool for biorefinery siting: using economic, environmental, and social metrics for a refined siting analysis', Biomass and Bioenergy.

Mathiyazhagan, K, S, Sudhakar \& Abhishek Bhalotia 2018a, 'Modeling the criteria for selection of suppliers towards green aspect: a case in Indian automobile industry', OPSEARCH.

Mathiyazhagan, K, S, Sudhakar \& Abhishek Bhalotia 2018b, 'Modeling the criteria for selection of suppliers towards green aspect: a case in Indian automobile industry', Opsearch, vol. 55, no. 1, pp. 65-84.

Matzen, Michael, Mahdi Alhajji \& Yaşar Demirel 2015a, 'Chemical storage of wind energy by renewable methanol production: feasibility analysis using a multi-criteria decision matrix', Energy, vol. 93, pp. 343-53.

Matzen, Michael, Mahdi Alhajji \& Yaşar Demirel 2015b, 'Chemical storage of wind energy by renewable methanol production: feasibility analysis using a multi-criteria decision matrix', Energy.

Parajuli, R, Dalgaard, T, Jørgensen, U, Adamsen, APS, Knudsen, MT, Birkved, M, Gylling, M \& Schjørring, JK 2015a, 'Biorefining in the prevailing energy and materials crisis: a review of sustainable pathways for biorefinery value chains and sustainability assessment methodologies', Renewable and Sustainable Energy Reviews, vol. 43, pp. 244-63.

Parajuli, R, Dalgaard, T, Jørgensen, U, Adamsen, APS, Knudsen, MT, Birkved, M, Gylling, M \& Schjørring, JK 2015a, 'Biorefining in the prevailing energy and materials crisis: a review of sustainable pathways for biorefinery value chains and sustainability assessment methodologies', Renewable and Sustainable Energy Reviews.

Pidol, Ludivine, Bertrand Lecointe, Laurie Starck \& Nicolas Jeuland 2012, 'Ethanol-biodiesel-diesel fuel blends: performances and emissions in conventional diesel and advanced low temperature combustions', Fuel, vol. 93, pp. 329-38.

Qi, HS, RN, Alzaabi, AS, Wood \& M Jani 2015, 'A fuzzy criticality assessment system of process equipment for optimised maintenance management', International Journal of Computer Integrated Manufacturing, vol. 28, no. 1, pp. 112-125.

Ren, Jingzheng, Suzhao Gao, Shiyu Tan \& Lichun Dong 2015, 'Hydrogen economy in China: strengths-weaknessesopportunities-threats analysis and strategies prioritization', Renewable and Sustainable Energy Reviews, vol. 41, pp. 1230-1243.

Robinson, Priscilla \& John Lowe 2015, 'Literature reviews vs systematic reviews', Australian and New Zealand Journal of Public Health, vol. 39, no. 2, p. 103.

Roozbehani, Behrooz, Saeedeh Imani Moqadam, Mojtaba Mirdrikvand \& Ali Cheshmeh Roshan 2012, 'Modeling direct ethylene hydration over zirconium tungsten catalyst: fundamental of ethanol production using the biggest global ethylene feeding pipeline in Iran', Energy and Environment Research, vol. 2, no. 2.

Samsuddin, Samsul Farid, Hayrol Azril Mohamed Shaffril \& Ali Fauzi 2020, 'Heigh-Ho, Heigh-Ho, to the rural libraries we go! - A systematic literature review', Library and Information Science Research, vol. 42, no. 1, pp. 100997.

Serna, J, Martinez, END, Rincón, PCN, Camargo, M \& Gálvez, D 2016, 'Multi-criteria decision analysis for the selection of sustainable chemical process routes during early design stages', Chemical Engineering Research and Design, vol. 113, pp. 28-49.

Singh, Rajesh Kumar, HR Murty, SK, Gupta \& AK, Dikshit 2012, 'An overview of sustainability assessment methodologies', Ecological Indicators, vol. 15, no. 1, pp. 281-299. 
United Nations 2020, 'The 17 GOALS | Sustainable Development', Department of Economic and Social Affairs.

Wang, Hao, Yanpeng Cai, Qian Tan \& Yong Zeng 2017a, 'Evaluation of groundwater remediation technologies based on fuzzy multi-criteria decision analysis approaches', Water, MDPI, vol. 9, no. 6.

Wang, Hao, Yanpeng Cai, Qian Tan \& Yong Zeng 2017b, 'Evaluation of groundwater remediation technologies based on fuzzy multi-criteria decision analysis approaches', Water, MDPI, vol. 9, no. 443.

Wang, Lei, Qing Liu \& Tongle Yin 2018a, 'Decision-making of investment in navigation safety improving schemes with application of cumulative prospect theory', Proceedings of the Institution of Mechanical Engineers, Part O: Journal of Risk and Reliability.

Wang, Lei, Qing Liu \& Tongle Yin 2018b, 'Decision-making of investment in navigation safety improving schemes with application of cumulative prospect theory', Proceedings of the Institution of Mechanical Engineers, Part O, Journal of Risk and Reliability, vol. 232, no. 6, pp. 710-724.

Yang, Z, Song, J, Cheng, D, Xia, J, Li, Q \& Ahamad, MI 2019, 'Comprehensive evaluation and scenario simulation for the water resources carrying capacity in Xi'an City, China', Journal of Environmental Management, vol. 230, September, pp. 221-233.

Yazdi, Mohammad \& Sohag Kabir 2017a, 'A fuzzy Bayesian network approach for risk analysis in process industries', Process Safety and Environmental Protection.

Yazdi, Mohammad \& Sohag Kabir 2017b, 'A fuzzy Bayesian network approach for risk analysis in process industries', Process Safety and Environmental Protection, vol. 111, pp. 507-519.

Yazdi, Mohammad, Arman Nedjati \& Rouzbeh Abbassi 2019a, 'Fuzzy dynamic risk-based maintenance investment optimization for offshore process facilities', Journal of Loss Prevention in the Process Industries.

Yazdi, Mohammad, Arman Nedjati \& Rouzbeh Abbassi 2019b, 'Fuzzy dynamic risk-based maintenance investment optimization for offshore process facilities', Journal of Loss Prevention in the Process Industries, vol. 57, pp. 194-207.

Zhao, Fu, Vance R, Murray, Karthik Ramani \& John W, Sutherland 2012, 'Toward the development of process plans with reduced environmental impacts', Frontiers of Mechanical Engineering, vol. 7, no. 3, pp. 231-246. 